\title{
PAPERLESS PLANTS FOR COMPONENT SYSTEMS BUILDING (CSB)
}

\author{
Antti Nurminen \\ Makron Oy, Norokatu 4 \\ SF-15101 Lahti,Finland
}

Abstract: An automated CAD/CAM -system for wood frame wall panel manufacture is presented. The Paperless Plant -philosophy based Computerized Wall Panel -system is blueprint free and utilizes leading edge CAD and Automation technologies resulting in increased productivity, labor savings and increased quality of the end products.

\section{INTRODUCTION}

In rich developed countries, the construction industry is facing shortage of (skilled) labor, on site works in particular. This results in high salaries, high costs and in a risk of falling behind of tight schedules. This situation is caused by the working environment and conditions prevailing on construction sites and in many factories as well. This syndrome is characterized by three attributes, which can be called 3 Ds (synonymous with the famous Japanese $3 \mathrm{Ks}(5 \mathrm{Ks})$ for Kitanai, Kitsui and Kiken) ie Dirty, Difficult (also Dull) and Dangerous. Industrialized building construction and automation is the answer to this predicament. Three alternatives are put forward below (see figure 1).

\begin{tabular}{|c|c|c|}
\hline $3 \mathrm{Ds}$ & & \multirow{2}{*}{ (4) O Tupamăki 10 Sep 91} \\
\hline $\begin{array}{l}\text { Dirty } \\
\text { Difficult } \\
\text { Dangerous }\end{array}$ & & \\
\hline \multicolumn{3}{|l|}{ AUTOMATION } \\
\hline \multicolumn{3}{|c|}{ Information Technologies, Processes, Systems, Robotics etc } \\
\hline$\checkmark(1)$ & $\checkmark(2)$ & $v^{3}$ \\
\hline $\begin{array}{l}\text { COMPONENT SYSTEM } \\
\text { BUILDING;COMPONENTS } \\
\text { PRE-MANUFACTURED }\end{array}$ & $\begin{array}{l}\text { CONSTRUCTION } \\
\text { USING (AUTOMATION)/ } \\
\text { ROBOTS ON SITE }\end{array}$ & $\begin{array}{l}\text { BUILDINS SYSTEMS } \\
\text { SUITATLE FOR } \\
\text { AUTCMATION/ROBOTS }\end{array}$ \\
\hline $\begin{array}{l}\text { MIT, VTT } \\
\text { Partek etc }\end{array}$ & $\begin{array}{l}\text { Taisei } \\
\text { Shimizu }\end{array}$ & $\begin{array}{l}\text { Obayashi } \\
\text { Taisei }\end{array}$ \\
\hline$\downarrow$ & $\downarrow$ & $\downarrow$ \\
\hline YES & No & $?$ \\
\hline $\begin{array}{l}\text { Easy to utilize automation } \\
\text { in permanent, controlled } \\
\text { factory environment. } \\
\text { Good for all sizes of } \\
\text { individual nojects. }\end{array}$ & $\begin{array}{l}\text { Hard :o utilize } \\
\text { sutomation due to } \\
\text { unique difficult site } \\
\text { environment. } \\
\text { Suitable for limited } \\
\text { works on large } \\
\text { projects. }\end{array}$ & $\begin{array}{l}\text { Possible to utilize } \\
\text { automation. } \\
\text { May be suitable for } \\
\text { large/high-rise or } \\
\text { standardized repetitive } \\
\text { projects. }\end{array}$ \\
\hline
\end{tabular}

Figure 1. Three Alternatives for Automation and Robotics in Construction [1]. 


\section{THE TRADITIONAL WAY}

The wood frame wall panel consist typically of the frame with 2" x 4 "lumber plates and 2" x 4" studs 16 " on center. For interior walls the panel is just the frame. Exterior walls have different kinds of sheathing (OSB, Foam, particle board) attached on the exterior side of the panel providing wind blocking, required rigidity and insulation for the panel. This is the most common type of panel used in panelized house building in the United States with hundreds of thousands homes built every year.

Wall panels are either manufactured at the site i.e. "stick-build" or at the plants. Stick building is labor intensive, time consuming and sensitive to bad weather conditions. The typical wall panel manufacture system in commercial plants has been a metal table that adjusts and clamps for different wall panel heights but, is restricted by its length. The metal table is hand-loaded with pre-marked top and bottom plates, studs and subassembly components. However, securing a square wall panel is difficult to achieve because metal table clamps only from one direction. Nailing is performed by hand-held tools or tools attached to carriages running the full length of the table.

\section{THE PAPERLESS PLANT -PHILOSOPHY}

In order to remain on the cutting edge of the industry one must take the advantage of the latest automated technology by letting the machinery do the tedious work. The Paperless Plant -philosophy eliminates blueprints from the plant floor with tight integration of the design and manufacturing systems providing progressive panel manufacture system with streamlined material and data flow.

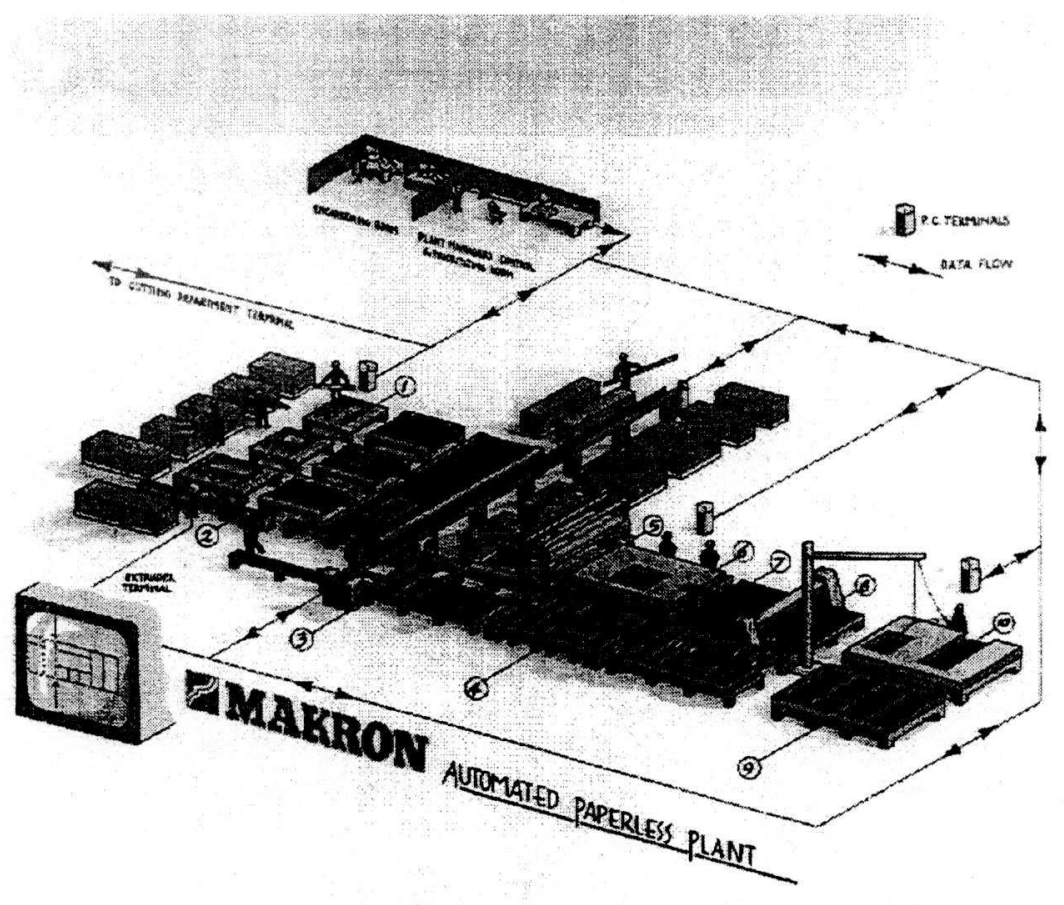

Figure 2. Makron Automated Paperless Plant for Wall Panels 
The house designs are entered into the CAD-system which generates several schedules of cutting lists, assembly diagrams, stacks just to mention a few. These schedules are directly used at each workstation through a monitor screen. There is no more need for blueprints on the shop floor.

The machinery is operated by PLC, which controls all function movements and working cycles. All setups take place automatically. A PC is included with each station to receive data directly from CADsystem. At Extruder the data is converted, using an integrated program which instructs the Extruder on how many times to nail and how far to move the wall frame for placement of the next stud or subassembly component. The program is displayed on a computer monitor which tells the operator what component to place into the Extruder next. The CAD-design of the panel also highlights what components are to be put in place and nailed. The information and material are received on demand, promptly and accurately.

Utilizing components and state of the art "on demand" technology, production lines can be directly controlled. This technical "tie-in" eliminates human error and automatically initiates and controls movement of the panel frames on the production line. Even the squaring of the panel is automatic and take place repeatedly in order to secure the best possible result. Other industries have been successfully using this kind of systems to transfer data directly to machinery for many years. Automation improves dimensional quality, shortens production time and, reduces manufacturing defects.

\section{COMPUTERIZED WALL PANEL SYSTEM}

The CAD generated data is directed to the plant manager's PC in which each job is prioritized. All the data is prioritized in relation to a just-in-time procedure for a flow of material to the production lines.

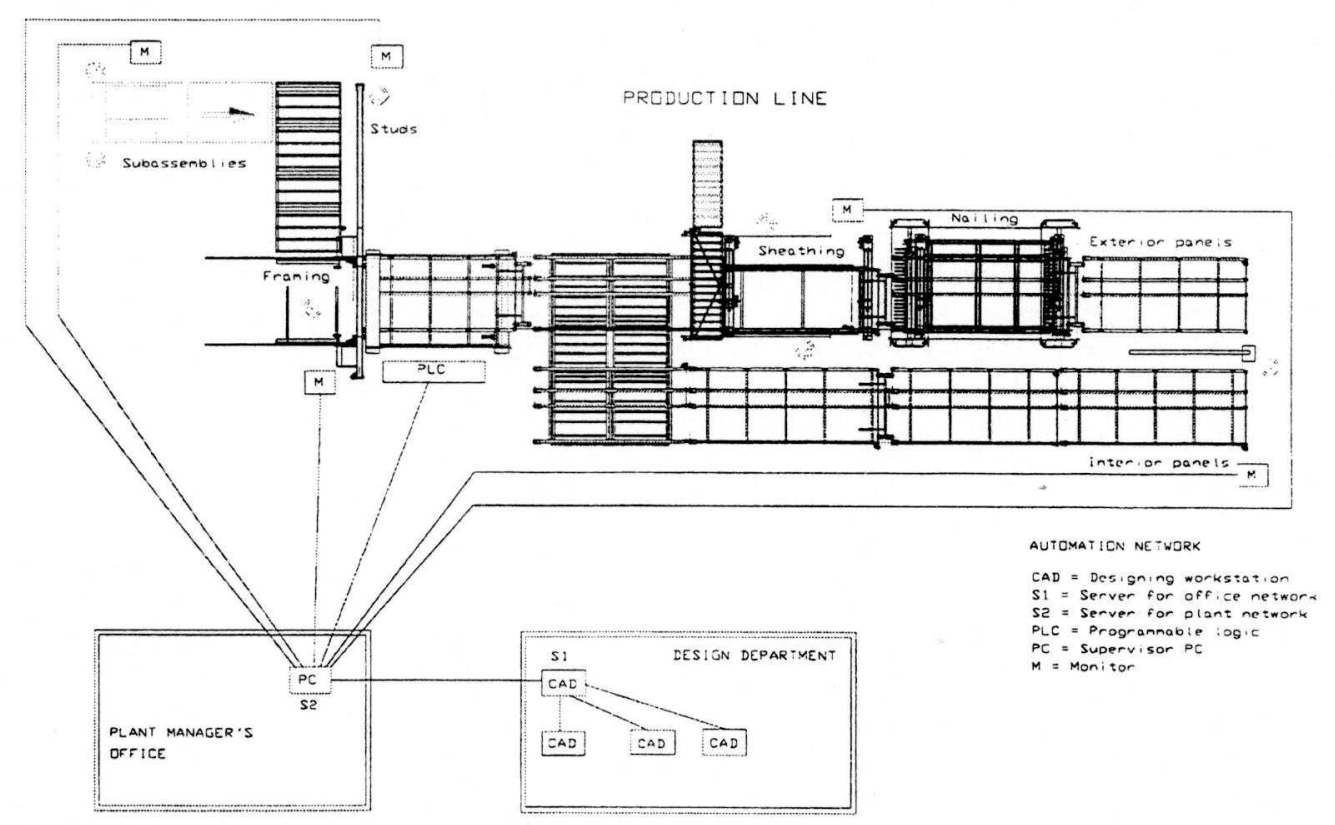

Figure 3. Computerized Wall Panel -system. 
Production sequence is house by house and production order of panel is according to stacking i.e. installation order. Plant manager can change production order from his PC. Line itself operates automatically according to data generated in the $\mathrm{CAD}$-program.

The plant manager's computer puts the house design's panelization data into a production schedule. When it is this home's turn to be manufactured, the panelization data is transferred to the computer on the shop floor. This computer instructs the production line's computer - the PLC - to coordinate and display the directions for the production line. These directions include placement of the wall members, nailing, and the movement of the conveyors.

The production is divided into a number of separate stations. Each station has its own PC-monitor providing the accurate and sufficient just-in-time information of the panel, stack, home and project to be manufactured. The stations are cutting saw(s), subcomponent assembly station(s), Extruder(s), Windbrace Saw (exterior panels), Sheathing Table, Fastening Bridge, Router Bridge and Panel Stacker. The movement of the panels and subcomponents are performed by a system of conveyors and rollers. There is also a separate cell to manufacture and assemble special panels like gable-end wall panels.

\section{OPERATION DESCRIPTION}

Sawing, storing and other premanufacture material handling operations are not discussed here. But as a thumb rule and depending on the space limitations and capacity requirements, sawing operations may divide into 1-3 different saws; plates, cripples, headers and other subcomponents. Sawing operations can utilize the same information produced by the CAD-system and the same Paperless philosophy as described above. A station to manufacture special panels is also required and may include a saw.

\subsection{Subcomponent Assembly Station}

Wall panel manufacture begins at the a jig table where 2-3 workers assemble precut window and door knockouts, ladders and other subcomponents. A worker places these assemblies and framing studs on two conveyors. A monitor at this station displays the proper order in which to place the members on the conveyors. The conveyors feed the members in a just-in-time schedule to the Extruder operator. He puts the panels together according to instructions displayed on a monitor at his station.

\subsection{Extruder(s)}

The Extruder is a stationary machine built especially for squaring and nailing of exterior and interior wall panels and thus used to assemble them. For capacity reasons there may be a separate Extruder with complete lines for both exterior and interior panels. All studs, top and bottom plates and subcomponents are fed into the Extruder which will then square and nail the wall panels on a continuous basis. Wall heights of 4 to 12 feet can be accommodated. The biggest advantage of the Extruder is that Set-Up Times are eliminated completely. 


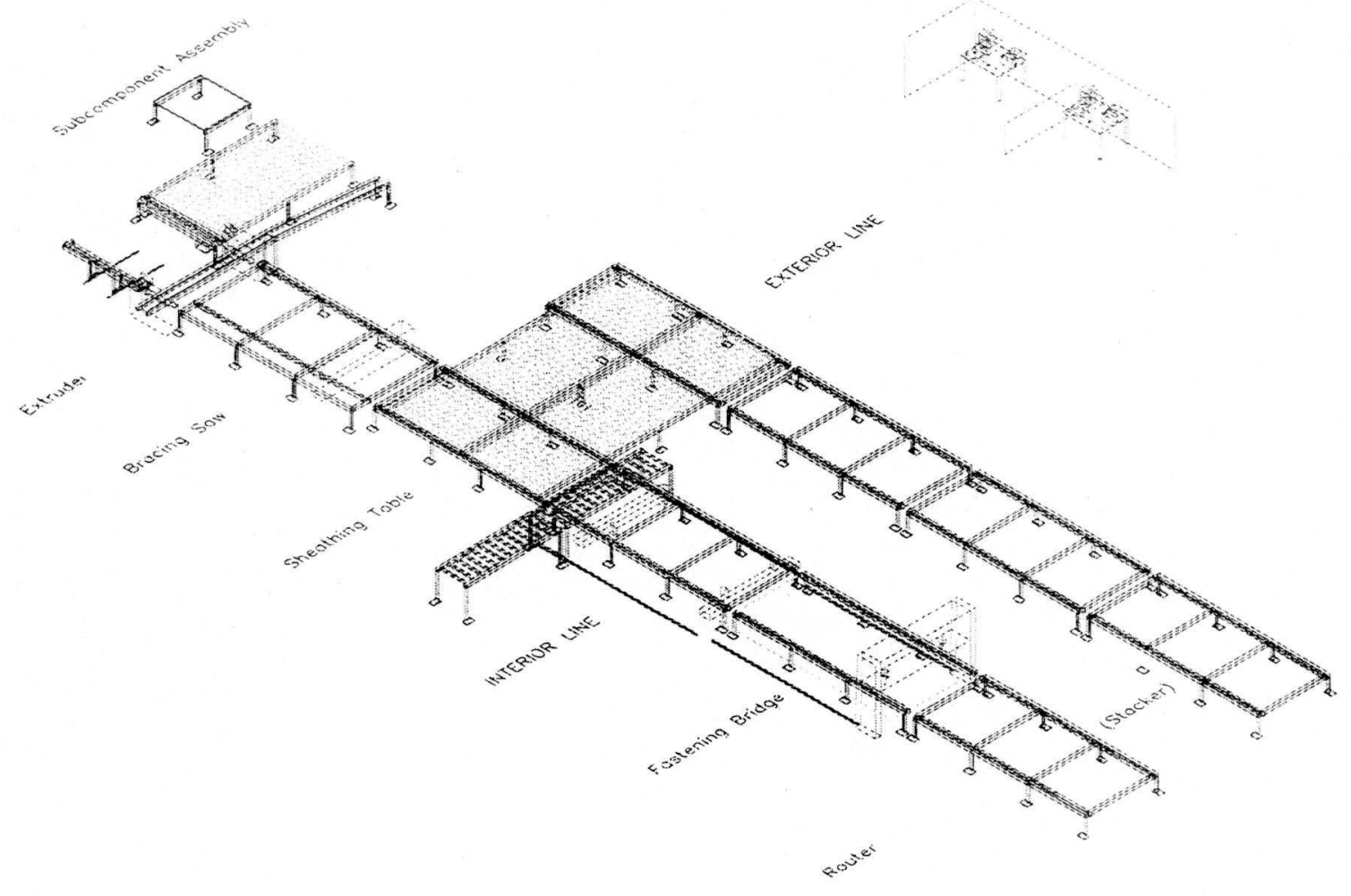

Figure 4. Computerized Wall Panel -system layout.

A clamping and nailing bridge pulls the frame through the Extruder automatically fastening the subcomponents, studs and top $\&$ bottom plates. In a perfectly square manner, the bridge pulls the frame to the exact point where the operator inserts the next member. Adjustments are made with an easy to operate control panel, entry pad and monitor.

The nailing tools are built into each side of the Extruder and are operated automatically; they are safely out of reach of the operator. Each nailing tool on the Extruder is equipped with a high-load coil containing e.g. 1000 nails, therefore minimizing reloading time. The Extruder is activated and controlled by a Programmable Logic Controller (PLC) utilizing data generated in the CAD-program.

On the interior panel line the panels leaving the Extruder are automatically conveyorized to the end of this line where automated Panel Stacker places them on a pallet stack. If there is a wall panel not yet lifted from the line, the next panel automatically waits for clearance to proceed. On the exterior panel line panels continue to the next station to be braced, sheathed and/or stacked.

\subsection{Windbrace Saw}

When metal bracing is required by the building code, the Windbrace Saw cuts a groove with various left or right angles in the exterior wall panel according to the CAD-system instructions so that (metal) bracing can be installed. Automatic height adjustment is provided according to various thicknesses of the panels as well as groove depth according to the panel type. 


\subsection{Sheathing}

In the following sheathing related operations are described as separate operations that can take place in different configurations of machinery i.e. some of the operations can be combined to be done in one or more machines depending on the requirements and set-up. As an example some specific machines are referred to.

\subsubsection{Squaring/ Sheathing}

When wall panel require sheathing, the system automatically knows what panels to forward down the production line. The CAD-data, stored in the computer, will tell the system what panels require sheathing and fastening and which do not. Without operator assistance, the panels will either continue to the fastening (stapling) bridge or be transported to the finished area for stacking.

By using squaring stops and side squaring device, the Squaring/Sheathing Table squares the wall panels for placement of various sheathing materials (e.g. Plywood, OSB, foam, sturdy bracing, dry wall) in typical thickness of $1 / 2$ ". The squaring stops are lowered out of the way so the next wall panel can enter the Squaring/Sheathing Table.

\subsubsection{Fastening}

The Fastening Bridge attaches the sheathing to the wall panels. The CAD-system tells the Fastening Bridge to allow for proper spacing to meet strict building code requirements. The bridge holds numerous pneumatic staplers/nailers held 6" apart on a side-moving arm to obtain 3" centers on sheathing seams.

Different fastening patterns may be programmed for building code compliance and automatic adjustment for different panel thickness and sheathing material thickness/softness is provided. Each tool is operated independently or as a group.

\subsubsection{Routing}

By following the CAD-system instructions the Router automatically cuts openings in the sheathing material to match the window and door openings, beam pockets and sheathing laps. Router may be a robot arm with spindle, $2 \frac{1}{2} 2$-axis CNC-machine or PLC-driven bridge.

\subsection{Panel Stacker}

The Panel Stacker is self contained with structural supports enabling it to pick up panels from either exterior or interior wall panel lines capable to serve them both. It can turn the panels up to 90 degrees to stack them according to delivery or handling requirements. 


\section{CONCLUSIONS}

Basing on the real life Computerized Wall Panel -system experience the Paperless Plant -philosophy provides the following benefits:

- increase of overall capacity and better utilization of factory space and/or

- reduction of labor; up to $1 / 3$ labor savings can be achieved

- increased productivity with flexible production capability

- reduce the needless movement of material

- enable high quality production

- enable short pay-back time

- ensure user friendly equipment and

- ensure low cost maintenance.

\section{REFERENCES}

1. O.Tupamaki, Betonwerk + Fertigteil -Technik (BFT) Nr. 1/93, Bauwerlag GmBH, Wiesbaden, Germany 